\title{
The Current Need to Develop a Social Policy on Leisure(s)/Recreation from a Personalist Point of View - A Brief Look at the Canadian Reality
}

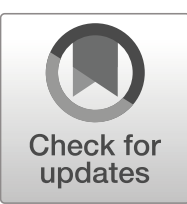

\section{Gervais Deschênes ${ }^{1}$ (1) $\cdot$ François Gravelle ${ }^{1}$}

Received: 28 April 2020 / Accepted: 16 July 2020/Published online: 25 July 2020

(C) Springer Nature Switzerland AG 2020

\begin{abstract}
This conceptual article looks at some benchmarks about the need to develop a social policy on leisure(s)/recreation in Canada. In fact, there is a fundamental movement to ensure that this global earthly reality with many dimensions, including sporting practices, are subject to a more rigorous legislation by meeting the urgency of the situation caused firstly by the misunderstanding of the monochrone and polychrone time as well as the episodic socio-economical problems. Relationships between three humanity models, namely - the homo faber-person at work, the homo religious -person-related-to-the-religious/spiritual, and the homo ludens - person at play - are inextricably linked and implied the spiritual model of leisure(s) entitled the homo faber-religious-ludens where persons can identify themselves through the specificity of this continuum within the post-secular era. Some pragmatic stance is finally taken to create a better synergy of leisure(s)/recreation and sporting practices regenerating the social fabric about the Canadian mosaic perspective in the communities of the social world especially from the personalist point of view which will also have a beneficial health outcome during this sanitary crisis cause by the Covid-19 pandemic context on Earth.
\end{abstract}

Keywords Leisure(s)/recreation social policy · Spiritual well-being/spiritualities · Personalism · English and French connections/Canada

Gervais Deschênes

gdesche2@uottawa.ca

François Gravelle

fgravel@uottawa.ca

1 Faculty of Health Sciences, School of Human Kinetics, University of Ottawa, 125 University

Private, Ottawa, Ontario K1N 6N5, Canada 
"My only country is your face".

— Gilbert Langevin (1938-1995)

"Though we all eventually retire from work, you don't retire from leisure(s)".

— Joffre Dumazedier (1915-2002)

\section{Introduction}

This conceptual article propounds a few benchmarks to 'explain more' in order to 'better understand' the need to develop a social policy on leisure(s)/recreation. ${ }^{1}$ It will bring to the fore the global earthly reality ${ }^{2}$ of leisure(s)/recreation, including sporting practices, for a beneficial public debate in which we would encourage discussion and conversation in genuine mutual dialogue. It will also provide a clear picture of a few key elements to be used in configuring a unifying definition of leisure(s)/recreation in order to set in motion the foundations of this "unthinkable known" (Moulaert et al., 2015). Persons experience ethicalspiritual moments that appear in intermittent and successive images in their consciousness and around their natural environment, promulgating the social and spiritual significance of leisure(s)/recreation. More precisely, since these ethical-spiritual moments are predetermined and self-regulating for people as persons, ${ }^{3}$ they maintain the processes of humanization that quickly bring forth some existential questions. This reflection starts off, with the initial question: How to live? A second question is: How to develop an innovative modus vivendi ${ }^{4}$ ? Finally, since leisure(s)/[recreation] concern people and are phenomena of life (Arendt 1972), a third question is then suggested: How to experience an art of living? These three existential questions confirm the assertion of Ricœur (1992, p. 352) stating that " (....) the search for the choice appropriate to the situation, is to recognize oneself as being enjoined to live well with and for others in just institutions and to esteem oneself as the bearer of this wish". The Ricœurian philosophical approach necessarily implies a quest for self-knowledge, delegated team research and genuine cooperation towards an ultimate goal to be achieved in time and place because leisure(s)/recreation is essential to spiritual wellbeing for persons. They are clearly in the process of discovering their own realm. It is not just a privilege, there is also an intrinsic need to be entertained and to rediscover the sense of life that generates hope and creative optimism.

\footnotetext{
${ }^{1}$ The concepts 'leisure(s)' and 'recreation' are both employed to better qualify the quality of life in Canada. This discrepancy in terms has caused over time an epistemic debate. Basically, the term, 'loisir(s)' is recognized in the francophone culture whereas 'recreation' is well established in the anglophone culture.

${ }^{2}$ The expression earthly reality is a notion from holy scripture that is concerned with worldly affairs. It therefore studies experiences on Earth in spite of the pain and toil they represent upon discovering them. Since the 1950s and up to and including the present time, leisure(s), recreational and sporting practices have been considered in the Catholic Church and the laity, both in France and in Quebec, as a burgeoning field of study in terms of their progressive exploration and promotion in the communities of the social world.

${ }^{3}$ As this text contains a profound philosophical and theological approach according to the anthropological transformation from the personalist point of view, the notion 'persons' is then referred most of the time in this conceptual article whereas the word 'people' is sometimes used to allow a better flow in the writing.

${ }^{4}$ The term modus vivendi was used by Professor John Zauhar (1985) from the University of Ottawa in one of his courses entitled Education/Counselling en loisir. Even if its translation means mode de vie, its referential is the leisure(s) notion of lifestyle well defined by Professor Jean-Louis Paré $(1985,1997)$.
} 
Furthermore, it must be said that history is the tragedy of a humanity which makes its history, but which does not know the history which it makes (Weber 1919/1959). For Berger and Luckmann (1966), the social everyday reality is a collective project which unfolds in an intersubjective manner that is shared with others who have dreams and appear to each person who lives in a common reality in the communities of the social world. As such, they emphasized that "compared to the reality of everyday life, other realities appear as finite provinces of meaning, enclaves within the paramount reality marked by circumscribed meanings and modes of experience" (Berger \& Luckmann 1966, p. 25). Therefore, the meaning of each person is also the meaning of everybody with goodwill in the global earthly reality. This is why it is imperative that in all spheres of life, each person will have to decide from their own point of view (Weber 1919/1959). The sacredness of persons is then fundamental. For Gallant et al. (2013), leisure(s)/[recreation] by itself communicates a fundamental connotation by which each person is immersed in forging bonds in the communities of the social world. Through this approach, the ethical-spiritual moments of persons carry many spiritualities that enable them to enjoy life to the fullest in social and temporal contexts that are truly life-giving and playful through the re-enchantment on Earth which is there in front of us (Berger 2001). This has a better synergy of leisure(s)/recreation and sporting practices regenerating the social fabric in the communities of the social world especially from the personalist point of view which will also have a beneficial health outcome during this sanitary crisis cause by the Covid-19 pandemic context on Earth. As such, other systematic questions still remain:

Will leisure $[\mathrm{s}] /[$ recreation] in the future be simply an extension of the present, more of the same, or different in significant way? [...] What about various forms of 'time scarcity' that impact those with multiple jobs, extended hours, and heavy household and family responsibilities? [...] Will the leisure[s]/[recreation] of freedom and expression, of simplicity and the cultivation of human relationships, be valued more or less? (Kelly 2012, p. 220, 229, 233).

It should be clarified that our relationship to changing times and values recommends again fundamental questioning because of its vast complexity. For example, some persons will experience the increase in leisure(s)/recreation time in spite of themselves and will have to adjust according to their specific socio-economic situations. To counter these effects, we must finally answer the following question: What do persons really want to accomplish with respect to the temporal evolution of their earthly life? This conceptual article will therefore seek to outline the main metaphysical realities in the first two sections whereas the last section and recommendations look at the reality for the near future as possibilities by suggesting upon empirical challenges about the development of a social policy on leisure(s)/recreation in Canada.

\section{Time: A Rare Commodity}

To respond to the need to develop a social policy on leisure(s)/recreation, we are seeking to highlight the problem of time we have to live. In fact, for persons, free time without constraints is becoming increasingly challenging, with just taking the time to 
live becoming almost a privilege. Before the Covid-19 impact, the social world was marked by automatism and cybernetics, time contracts or accelerates in contemporary societies on Earth characterized by overproductivity, overconsumption, overperformance, extreme perfectionism and outrageous corporatism. For his part, Davidovich (2017) succinctly explains this problem of time linked to leisure(s)/ recreation:

Leisure $[\mathrm{s}] /[$ recreation] time, the time which is under the individual's exclusive control, is a test of the individual's personal, social, and national value system. Leisure[s]/[recreation] becomes a problem when the individual is unaware of the need to plan and direct it; when leisure[s]/[recreation] is considered 'empty' time, this vacuum can become filled with idleness, boredom, and an 'evil inclination'. Awareness of the value of leisure[s]/[recreation] and consequently, defining its goals and developing tools to accomplish them help fill the vacuum with content and meaning (p. 88).

Several leisure(s)/recreation specialists are wondering about the reasons for intervening adequately while respecting the person's freedom concerning his or her free time. For D'Amours (1987), it is the person's dearest and most intimate sphere of life. The concept of time is so intimate today that we must intervene because persons are so bewildered by the huge amount of free time they have on their hands that they don't know what to do with it, and this is true for a very large majority of the population. For Bellefleur (1975-1976), the philosophical term leisure(s)/[recreation] at its best is not just about management. It is defined above all by its ineffable indeterminacy. Nevertheless, leisure(s)/[recreation] refers to free time that we have in remainder and is explained as discretionary in that sense:

The most common understanding of leisure[s]/[recreation] today is that it consists of time free from work or work-related responsibilities, such as study, travel, or union activity. Typically, when the workweek is shortened or when holidays or vacations are added, economists conclude that employees have gained increased leisure. Other tasks required for self-maintenance, such as eating, sleeping, shopping, housekeeping, cleaning, or obtaining medical care, are also regarded as obligatory uses of time, and so are not considered to be forms of leisure[s]/ [recreation] (Kraus 2000, p. 8).

Surely, free time is becoming more and more important for persons who wish to live a successful life. For them, work is not the end of everything. There is a personal need to set new priorities. As such, time is the most precious and sacred thing. The persons are aware to evaluate their time use chronologically or mechanically, defining themselves as follows:

Time Use considers how people experience and spend their time. It means how the use of our time affects physical and mental wellbeing, individual and family wellbeing, and present and future wellbeing. It examines the length of our work week, our work arrangements, our levels of time pressure, and the time we spend with friends and in other free-time activities (CIW 2016, p. 48). 
Using this non-restrictive definition, it is interesting to outline namely some Canadian trends in time use as set out in the Canadian index of wellbeing. Looking at this analytical study enables us to see recently what is problematic about the organization of quantitative time in the social world:

- $[\ldots]$ Fewer of us are working long hours and we have more flexibility (Fewer Canadians are working more than 50 hours per week/Flexible work hours are more widely available);

- $\quad[\ldots]$ But more are working irregular hours and shorter hours not by choice (Fewer workers have regular daytime hours/The greatest impact is in low income households/Women are more likely to be underemployed);

- Canadians continue to feel the 'time crunch' (1 in 5 Canadians feel high time pressure);

- Time spent commuting to work continues to rise (By 2014, daily commute times were nearing 1 hour for working Canadians);

- We are getting less quality sleep (Only 1 in 3 Canadians are getting enough sleep); and

- $\quad[\mathrm{We}]$ are spending less and less time with friends (time spent with friends each day is down 30\%) (CIW 2016, p. 50-52).

From this point of view, the management of time is a problem to be eventually resolved generates by the concept of time famine which is the "primary concern are perceptions people have their lives are 'rushed', that they do not have enough time to fit in everything they want to or should do" (Robinson \& Godbey 1997, p. 230). Life is then a race against time (Sue 1994). We also note that in terms of time perception for the Canadian population aged 15 and over, $47 \%$ of people feel tense about the lack of time, $41.5 \%$ have the impression that they haven't accomplished what they wanted to accomplish by the end of the day, $27.7 \%$ don't have time to have fun, $32.3 \%$ worry about not spending enough time with their family and friends and $25.1 \%$ consider themselves to be workaholics (Statistics Canada 2018). These existential realities are not new. Seneca (AD 49-55/1994) already knew perfectly well that the existential length of life is very short and that, in terms of quality of life, it is more useful to devote one's life entirely to leisure(s)/recreation in order to get to know yourself better rather than occupying oneself with a life dedicated exclusively to work. It is therefore essential to better define our relationship with time. Of course, time undeniably slips through our fingers in the face of the ephemeral dimension of our contemporary societies (Lipovetski 1987). This dimension constitutes an anti-value and is often determined by the behaviour of every-man-for-himself, i.e., societies advocating an egotistical individualism characterized by postmodernism (Lipovetski 1983). This current of thought has a perverse effect since it most often seeks to shift blame and problems towards other places. In that perspective, individuals are no longer seen as full-fledged persons. However, in the mystical world of persons, each person is the bearer of his or her own time. It is important to appreciate and better understand what the notion of a person underlies through the flow of time on Earth in a fragmented social world:

I am $a$ being, in the singular, I have a proper name-a unity that is not the dead identity of a stone which is neither born, nor lives nor grows old. Nor is this unity of a whole which one can embrace in a formula. [Also vocation] is a word rich in meaning to one Christian, who believes in the all-embracing of one Person. But a personalist standpoint is sufficiently defined even in this thought-that the 
significance of every person is such that he is irreplaceable in the position he occupies in the world of persons (Mounier 1952, p. 41).

Each person has his or her own properly structured temporal existence with sufficient compassion and care to live. Yet time is a complex and ambiguous notion. It involves, for example, two forms of unfolding in its lived conception: 1) mechanical/objective/ monochronic or 2) qualitative/subjective/polychronic. In addition, for Hall (1983), monochronic time is a measure that is masculine, poor, physical, biological and secular. It is organized around the work of the technoscientific society whose mechanics are those, for example, of the hourglass, the clock, the watch, the calendar-which are the main frames of reference specific to Western societies, where persons live accelerated lives. Each person doing one act at a time in a closed system. For its part, polychronic time is an ontological, feminine, rich, existential, cyclical, temporal, metaphysical and sacred notion. It is updated in contemporary societies that are considered traditional through play situations, whether they be educational, cultural or social characteristics of agrarian societies in which life is slower and more in tune to the natural environment. However, with the invention of the Internet and more recently of the smart phone that gives the possibility to provide persons to be 'on call', in contact any place and any time as well to screen each other (e.g., Robinson \& Godbey 1997), polychronic time has become accelerated in various contemporary societies in general and more particularly in the young hypermodern generation, which is projected - without always being really aware of it - into a virtual or probably a superficial world. It is an open system by which we do several actions at once or in synecdoche. Here are some elements of definitions of monochronic and polychronic time proposed by Hall (1983):

\section{Monochronic Time}

M-time can alienate us from ourselves and from others by reducing context. It subtly influences how we think and perceive the world in segmented compartments. This is convenient in linear operations but disastrous in its effect on nonlinear tasks. M-time, on the other hand, is oriented to tasks, schedules, and procedures. (...) As anyone who has had experience with our bureaucracies knows, schedules and procedures take on a life all their own without reference to either logic or human needs. And it is this set of written and unwritten rules - and the consequences of these rules - that is at least partially responsible for the reputation of American business being cut off from human beings and unwilling to recognize the importance of employee morale (p. 46, 50).

\section{Polychronic Time}

Polychronic cultures are by their very nature oriented to people. Any human being who is naturally drawn to other human beings and who lives in a world dominated by human relationships will be either pushed or pulled toward the polychronic end of the time spectrum. If you value people, you must hear them out and cannot cut them off simply because of a schedule. (...) [P] olychronic individuals are oriented toward people, human relationships, and the family, which is the core of their existence. Family takes precedence over everything else. Close friends come next. In the absence of schedules, when there is a crisis the family always comes first (p. 50, 51). 
For a better understanding of time, Paplauskas-Ramunas (1960) sets out a difference between measure and rhythm. Measure means number, quantity, repetition, immutable, artificial and monotonous. This way of being is associated with a life inspired by machinism, even monochronic time. Moreover, the measure is associated with the constraints of work, with the limits of linear time imposed by contemporary societies. However, rhythm means alternation, perpetual renewal, vital impulse. It involves all the variety and diversity of forms of life. Rhythm is therefore a personal reality that is based on foundations that relate to one's genetics, life history and deep personality. According to Bobe (1925 in Paplauskas-Ramunas, 1960), machinism, even measurement, would have distanced modern beings from the normal rhythm of life, would have made them too angry, unbalanced, put them off-centre and made them dysfunctional. Paplauskas-Ramunas (1960) cites Collier in Nash (1953) in his remarks on the fullness of life through leisure(s)/recreation by claiming that they would be the remedy or the antidote to machinism. From there, the persons are able to return to a more balanced personal rhythm of life conditioned by the experience of ethical-spiritual moments. By moments, we mean a notion of more or less long time allowing each person to find themselves in a specific learning situation (Chamberland et al. 2011). The part containing the term ethical seeks to answer firstly the questions: What can I know? What can I do? What do I have to hope for? (trans. Kant 1781/1987). These ontological questions are part of the continuous quest for the Kantian ideal of the sovereign good. More indeed, other questions come to our understanding: "Whose am I? To whom do I belong? To what am I committed?" (Spohn 2007, p. 24). The part involving the spiritual includes a notion of neutrality. It refers to "an intimate journey that a person takes to find the meaning of their own life" (trans. Demers 2008, p. 146). According to Lefebvre (trans. 2008, p. 188), spiritual/spirituality is defined as follows:

[...] something to do with meaning and consistency. It basically concerns the human capacity to attribute deep meanings (making meaning) to events, to personal experience, even to life itself, to have access in one way or another to the sacred or to transcendence, to discover at the bottom of oneself an infinite aspiration.

Spirituality often offers a sense of well-being, improves quality of life and provides social support (Bouwer 2013). More profoundly, spirituality refers above all to the mysterious dynamics that persons maintain with their Creator and they are often hidden realities [the mysterious dynamics] while contributing an aid that is adjusted so that the person can recover from situations of alienation and fragmentation. Spohn (2007) offers the following definition:

Spirituality is concerned not only with acts that are explicitly related to God but with the more pervasive awareness of God expressed by Ignatian spirituality as 'finding God in all things'. Its practices are not only the interior, rather, they integrate bodily actions and public commitments with convictions that are rooted in the person's affective and cognitive structure. Authentic spirituality is not confined to an individualistic 'care of the soul', since its practices and frame of reference are communally based and oriented to action with and for others (p. 36). 
The experience of ethical-spiritual moments is in itself a significant time of recovery and rest because it is above all a vector of humanization, carrying meaning and regeneration of life. It enables one to rediscover their true identity after having been injured by misunderstanding and misuse of monochronic and polychronic times in the spheres of life that are family, work, free time, leisure(s)/[recreation], socio-political engagement, friends.

\section{Implementation of the Spiritual Model of Leisure(s)}

\subsection{Homo faber-religious-ludens in the Development of a Social Policy on Leisure(s)/Recreation}

Lifestyles call for the establishment of a spiritual model of leisure(s) that is inextricably linked to our relationship with time. In fact, these lifestyles shape the communities of the social world. They deserve to be used as inspirations in order to reflect more properly on their impact in the co-elaboration of meaning and knowledge about the need for the development of a social policy on leisure(s)/recreation, because the quest for meaning through leisure(s)/recreation underpins the social functions of a successful life of discoveries, one that is connected, playful as well as being filled with hope and synergy (Iwasaki 2018). The spiritual model of leisure(s) is formally established by the diverse relationships and connections between these lifestyles; this model enables the helping of persons more easily by improving their leisure(s)/recreation praxis. Decision makers at many levels - of which we are many - will have to be attentive to these realities, which are part in the communities of the social world. That will enable them to better grasp the intricacies of the social changes to come so they will be able to provide elements of a solution and resolve certain problems concerning the moderate application of a social policy on leisure(s)/recreation. To achieve this, we suggest the lifestyles of the person-at-work, the person-related-to-the-religious/spiritual and the person-atplay, which are the empirical foundations of the spiritual model of leisure(s) entitled homo faber-religious-ludens (Bellehumeur et al., 2012; Deschênes 2011, 2015, 2016, 2018; Durand 1960/1992, 1964). These lifestyles are not isolated, analysed or justified separately. They form connections on a continuum by which the persons identify themselves best according to their social and personal situation in their everyday lives. They are thus in permanent contact with one another while providing social and spiritual meaning for an improved lifestyle. The relationships of reciprocity revealed by these lifestyles provide a significant anthropological transformation.

In general terms, the persons tend to follow the lifestyle of the person-at-work since the techno-scientific world meets persons' basic physiological needs. Kelly and Freysinger (1999) proclaim that around the work environment there is a pride to do a task well done; work is therefore a central identity for many persons. Nevertheless, the homo faber is submitted to the rule of the work ethos as being sometimes trapped in an iron cage (Weber 1904-1905/1964). Work by itself represents the notion of time because "[m]oney buys time, and time buys money, Time itself had become a commodity" (Schor 1992, p. 139). Persons determined to work more than necessary risk to suffer with more limited energy since "work in its broad meaning is the opposite of rest. [It] results in fatigue and often in boredom" (Parker 1983, p. 2, 33). However, the latter 
is not the only lifestyle that creates persons' identity and the flow of inner resources (Martin 1975). Thus play has a tremendous relevance for persons lives (Caillois 1958/ 1967). Person-at-play is a lifestyle which better defines the identity of persons in their everyday life, at least for a limited earthly time, who discover therein a renewed burst of inner resources with the intention of cultivating and deepening more the 'playing' nature of persons. These persons experience the surreal dimension of play since the characteristics of the irrationality of play is as follows:

[...] a free activity standing quite consciously outside 'ordinary' life as being 'not serious', but at the same time absorbing the player intensely and utterly. It is an activity connected with no material interest, and no profit can be gained by it. It proceeds within its own proper boundaries of time and space according to fixed rules and in an orderly manner (Huizinga 1955, p. 13).

In that sense, play is not foolish and is a serious matter because play is definitely a sign, as Berger declares (1970), of transcendence. As such, life is not only to be played in falseness, because deadly situations are by no means a game. The person-at-work and the person-at-play certainly need their interiority to be revitalized by the person-related-to-the-religious/spiritual. When these two lifestyles, with which persons most identify, are educated by the liberating teachings of the person-related-to-the-religious/spiritual as the ultimate revelation, then work and play come together, producing the state of mind of leisure $(s)^{5}$ through which they experience assured spiritual well-being. Sometimes the person-atwork is invited to rest and recharge their batteries through the person-at-play. They are both regulated through the deep direction of the person-related-to-thereligious/spiritual. The bonds created in these ternary relationships stimulate renewed energy by a return to work with the leisure(s)/[recreation] state of mind. Thus Parker (1975 p. 100) has these questions: "what is the relationship between behaviour and attitudes in leisure[s]/[recreation] and other spheres? To what extent can systems or action theory guide us in understanding leisure phenomenon?" It must be specified that from a personnalist point of view, the spiritual model of leisure(s) entitled homo faber-religious-ludens is above all a movement and not a system as such (Mounier 1952). Its definition is as follows:

Persons are fully engaged in the existential pursuit defined by the homo faberreligious-ludens for their inner and vital renewal process through the spiritual quest for leisure[s]/[recreation] in spite of the struggle of life. This situation is often characterized by persons working and playing with religious or spiritual attitudes. Therefore, persons may find their radical identity being at leisure[s]/ [recreation] in today's post-secular era (Deschênes 2016, p. 51).

\footnotetext{
${ }^{5}$ Neulinger (1974/1981, p. xii, xvii) has well circumscribed this concept of state of mind in enunciating: "To leisure means to be engaged in an activity performed for its own sake, freely and without pressure or coercion; it means doing something from which one derives meaning and satisfaction, and which involves one to the very core of one's being. To leisure means to be oneself, to express one's talents, one's capacity, and one's potentials. [...] Leisure is a state of mind; it is a way of being at peace with oneself and what one is doing".
} 
This definition subscribes to strengthening transcendent experiences and preserving mystico-spiritual advances. To this, in the wake of Dumazedier (1962, 1988, Pronovost et al., 1993), who was one of the initiators of the imaginary leisure(s)/[recreation] of the 1960s in the West, it is a question of detaching oneself from the stench of defeatism in order to persevere in our efforts to make decisions that are meaningful in terms of the spirituality of action that consolidates all the vitality and hope implied by a social policy on leisure(s)/recreation. Here we take up again the reflections of Dufour $(1968,1980)$, who-when referring to the sabbatical rest during those long mythological weekends - was already rightly announcing the exaltation and reconciliation with God, restoring our relationship to accelerated time towards a slower, even more synchronic time through events between persons and their interpersonal relationships, inscribed by more coherent gestures in accordance with the metabolic rhythm of the human body.

From that point of view, the religious/spiritual experiences of leisure(s)/[recreation] are the opposite of heightened, more intense work, as Pieper (1952) confirms:

Leisure $[\mathrm{s}] /[$ recreation], it must be clearly understood, is a mental and spiritual attitude-it is not simply the result of external factors, it is not the inevitable result of spare time, a holiday, a week-end or a vacation. It is, in the first place, an attitude of mind, a condition of the soul, and as such utterly contrary to the ideal of 'worker' in each and every one of the three aspects under which it was analysed: work as activity, as toil, as a social function. Compared with the exclusive ideal of work as activity, leisure[s]/[recreation] implies (in the first place) an attitude of non-activity, of inward calm, of silence; it means not being 'busy', but letting things happen (p. 51-52).

With the passage of time, the persons will become more aware that leisure(s)/ recreation improves mental and physical health by preventing illness insofar as possible. According to Karlis et al, (2002, p. 210), as a conclusive health outcome, leisure(s)/recreation are "connecting with God", "creating/finding meaning in life" and "connecting with self/others". In that sense, leisure(s)/ recreation are not a frivolous or secondary experience. They are the very foundations of what structures the totality of persons' identity. They contain a synergy within them because they are an integrating principle of the sacred. Leisure(s)/recreation is therefore part of personal development in the communities of the social world. Already, it is noteworthy to state that we are interdependent with one another (Cullis \& Suzuki 2010). Yet it is reasonable to believe what is often beyond human understanding when confronted with the visible and invisible universe of the cosmos:

Human beings have always believed in power beyond human power, life after death, and spirit-among-us (the sacred, the holy). But our cultural narrative does not include these beliefs, so our experience of them is stunted, truncated, painful. The consequences are threatening indeed-the denial of value, the negation of being. But if we look carefully, we will see that [...] the original story is still telling itself within us and around us, even in our de-spirited culture (Suzuki et al. 2007, p. 285). 
Leisure(s)/recreation are not limited to the religious/spiritual experiences of persons. They are also places of culture, where multifaceted values live. Yet, the problems of xenophobia and racism stemming from fear of the other give rise to ignorance and generate harmful ideologies. These can only be resolved through education that prevents alienation (Dumont 1981). It is a question of promoting more strongly the rights and freedoms characterizing the community spirit.

The problem of religious/spiritual tensions is resolved in good and bad times by a propulsive vision thanks to the need to develop a social policy on leisure(s)/recreation since our relationship to time is clarified in terms of more authentic and liberating values. The minority groups in the communities of the social world are faced with social injustices. Members of contemporary societies are all called together in non-ideological dialogue while recreating praxeological leisure(s)/recreation. That is how the telos specific to the image of a society is being made, through the benevolent quest for the pacification of persons. This is expressed through this singular dialogic capacity of them to reach out to others with trust, despite the existing prejudices leading to conflict in psychological, anthropological, cultural, mystical and religious/spiritual terms in circumstances where most persons are desacralized and secularized (Dufour 1980). Yet, beyond even appearances, they are more religious/spiritual than they actually think in their deepest selves, and in various ways more involved in the communities of the social world within the post-secularity era defined in its terms:

[...] modernisation of society does not lead simply to the disappearance of religion, but rather to a changed way of dealing with religion, as well as to its pluralization. The zero-point theory, honoured by secularization thesis, which holds that the more modernisation there is the less religion remains (and the opposite, the more religion there is, the less modernized a society is), no longer holds. Even more: whoever claims today that the outcome of social processes necessarily leads to a situation where religion may no longer have public meaning, and at best can be but a private matter, is unmasked as being ideological (Boeve 2012, p. 145).

Obviously, religion seems created various forms of spiritualities in the liberal international order where "God has been removed from the equation, but the Christian idea that the world is progressing towards some final object has remained" (Robinson 2019, p. 3). Thus the persons can not always behave as if God does not exist in the communities of the social world. For his part, Habermas (2019) recognizes the relevance of the positive social role of religion. He proposes encouraging the search for a new peaceful dialogue and coexistence between 'faith' and 'reason' in order to learn from each other within the post-secular era. It should also be noted that the post-secular sacramentality has mainly moved from the so-called institutional churches and has nevertheless been able to create a plurality of new ways of living out their renewed religiosities (Demers 2016; Heintzman 2000, 2008, 2009; Joblin 2009; Ouellette et al., 2011), starting from the spiritual model of leisure(s) that is homo faber-religious-ludens. 


\section{Relevance of the Need for the Development of a Social Policy on Leisure(s)/Recreation}

\subsection{Reflecting on the Canadian Reality ${ }^{6}$}

It is important to point out here that since the early 1990s, Taylor (1992) warned that the lives of many people were being atomized and fragmented, i.e., that this atomist perspective leads people to consider society from a purely instrumental point of view. But this [instrumental point of view] also accentuates that atomistic perspective because the absence of shared perspectives send people back to themselves. What is more, he also affirmed the relative difficulty of a human community to develop a common project. It is important to valorize efficient questions knowing that we can find the answer more often in the question than in the answer by itself. Therefore, Kelly (2012) recommends some additional questions in order to enhance the significance of such social policy on leisure(s)/recreation in contemporary societies that would find the necessity to develop a commitment about this thematic:

When political decisions are made and implemented, then the resulting consistencies become 'policy'. What are settled priorities? What kinds of activity are supported, ignored, or banned? To what extent are public agencies expected to control, manage, and give access to particular kinds of leisure/[recreation] resources: sports venues, natural environments, or arts performances? Decisions become policy. Provisions become taken for granted. Conflicting values are debated and adjudicated. Who makes the decisions? In a local community, an elected or appointed board usually decides on the funding of parks and recreation programs. Whom do those boards represent? What are the special interests, and how are they represented? What is the real power structure of the community? In a diverse society, which interests, styles, culture, and commitments come to gain public support while others are largely neglected? Leisure[s]/[recreation] is indeed political as well as personal (p. 105).

This section will therefore focus on providing some perspectives on the relevance of developing the social policy on leisure(s)/recreation in Canada that we understand in terms of public and political interest:

\section{Torjman's perspective (2005)}

A public policy is a deliberate and (usually) careful decision that provides guidance for addressing selected public concerns (p. 4).

\section{Lemieux's perspective (2009)}

[...] any measure adopted by a political system (state, regional government, municipality) or a quasi-political system (university, hospital, company, etc.) to regulate a situation which actors have succeeded in presenting as involving public problems, which can be reduced to problems of resource distribution and constraints within a community or from one community to another (trans. p. 324).

\footnotetext{
${ }^{6}$ The first two sections of the conceptual article focus on the metaphysical realities whereas the last section and recommendations look at possibilities for the near future by reflecting upon pragmatic solutions to a stepby-step development of a social policy on leisure(s)/recreation in Canada.
} 
In the following sub-sections, we will discuss the fundamental shift in the relevance of a national/[social] policy on [leisure(s)]/recreation as discussed by Storey (1990). Subsequently, we will discuss the urgent need for a unifying definition of leisure(s)/[recreation], which Burton (1977) argues is quite problematic. In addition, the summary description of $A$ framework for recreation in Canada: Pathways to wellbeing will be briefly reviewed in order to better understand this fundamental shift in the developing a social policy on leisure(s)/recreation in Canada. Finally, a few solutions will be briefly suggested to address a prelude to nationalwide reflection and also some perspectives related to time management.

\section{National/[Social] Policy on Leisure(s)/Recreation in Canada}

\subsection{A Fundamental Shift According to Storey (1990)}

Leisure(s)/recreation plays a major role in both personal and social quality of life. That makes it all the more relevant to develop a social policy on leisure(s)/recreation in Canada. We must remember Storey's (1990) waking dream, which predicted that the groundswell of the continual quest for a national/[social] policy on leisure(s)/recreation in Canada would tirelessly follow its course and become a tangible reality that cannot be so easily dismissed out of hand when he states with firmness:

[...] that the sphere in which people must find meaning and purpose is the family, the neighbourhood and the community; with its schools, churches, libraries and cultural institutions, sports groups and recreation clubs and social organizations. Programs of community activities are essential elements of life if people are to keep their sense of purpose and achieve happiness in a complex society. In their own communities ordinary citizens and their families can share with others the work of planning and carrying out projects for which they have recognized needs and set the goals. Here they can use their own methods and their own leaders for effective development (Storey 1990, p. 9).

Since time is a human issue that is part of the being-in-self, one of the primary goals of leisure(s)/recreation is to increase personal fulfilment, improve quality of life and regenerate the social fabric (Storey 1990). There is, therefore, a fundamental shift in support for a national legislative agreement on leisure(s)/recreation in Canada, one that is still needed and is of the utmost importance. However, the varying levels of government (i.e., federal, provincial, territorial and municipal) have been struck over the years by numerous socio-economic upheavals that have affected their stability and eroded political will and public awareness of the vital importance of leisure(s)/recreation as a social phenomenon. It is expected that the Canadian population will become increasingly aware of this fundamental shift of awareness as outlined by Storey (1990).

\subsection{The Need for a Unifying Definition of Leisure(s)/Recreation}

Burton (1977) confirmed the profound and recurrent symptoms of the disease afflicting Canada's public leisure(s)/recreation service system. One of those symptoms is that 
there is no clear, precise, explicit, unequivocal and unifying definition of this human praxis in Canadian society. This leads to confusion and territorial conflicts in the development of a social policy on leisure(s)/recreation in Canada. This situation is due chiefly to the fact that the hierarchies of bureaucratic structures are more focused on turning in on themselves because they are constituted in silos. Leisure(s)/recreation professionals should instead interact through a deliberative process to make informed decisions. Burton (1977) thinks brilliantly that the solution will come from the urgency of the situation itself. To overcome this situation, leisure/recreation practitioners in Canada should understand the dialectical relationships between monochronic and polychronic times in order to prevent and resorb episodic socioeconomic crises that are difficult to resolve. It is possible in that way to live in a more synchronic time, that is to say, one that is consistent with our renewed identity with the love and friendship that underlies it. Hence, public decision makers have to reflect properly on the growth of the Canadian population and the scarcity of material resources to be anticipated, as well as to make informed decisions regarding the environmental crisis to be resolved. These issues are sometimes intertwined through eclectic values advocating a society in which there is too often a display of noisy, flashy advertising that is entertaining, but which also makes people aware of the global earthly reality of leisure(s)/recreation. The levels of government will have to take into account all the opportunities offered by a social policy on leisure(s)/recreation in Canada, because this policy already has legislative parameters based on the real needs of leisure(s)/recreation, including sporting practices. They are as much a determining factor as health and education. They are highly valued by all persons in Canada.

One of the reasons for this relative difficulty in co-building and co-developing a unifying definition of leisure(s)/recreation lies in the Canadian specialist thinkers, who find themselves in endless and unnecessary bickering over terminology. Hence, it has been observed that there is a clear mistrust of one another. This state of affairs is not new and has been reflected in the academic careers of several Canadian thinkers specializing in leisure(s)/recreation matters, who work mainly in a vacuum locked in their own one-track thinking. Pageot (1977), for example, was an outspoken critic of institutions. He hypothesised that leisure(s)/[recreation] is not a means, but has its own end. However, leisure(s)/[recreation] are rather a means to a greater end (Deschênes 2007) but with this Canadian debate, it is necessary to rely on Kelly's (1987) American metatheoretical model who specifies that leisure(s)/[recreation] is a state of becoming revealing that they are not defined solely in terms of time, activity or management. On the contrary, it is a matter of considering leisure(s)/[recreation] as an evolutionary and complex process. This definite shift gives importance to the socio-historical and structural dimensions of leisure(s)/[recreation], which are conditioned for instance by culture, ethnicity, gender, social class, family and religion.

In order to avoid social inertia over leisure(s)/recreation, some feel that the ideal solution for reaching a unifying definition of leisure(s)/recreation would be to carry out a Delphi survey in concert with a nationwide consultation; the main Canadian specialist thinkers could use this as a means to agree in their own way about the building blocks of such a definition and the anchoring points of this social phenomenon could be solidified. In addition, this definition will have to be linked to the pulse of the general public because the activities of leisure(s)/recreation remains a lively experience of a religious/spiritual nature. Since all practice is necessary ahead of theory, the social 
achievement of a definition should not come solely from Canadian specialist thinkers themselves, but it must first and foremost come about by listening to the experiences of leisure(s)/recreation practitioners ${ }^{7}$ through a simultaneous qualitative study of a phenomenological nature as well as a quantitative empirical survey, thus fuelling a healthy public debate. A common and inclusive definition of leisure(s)/recreation will therefore respect the inalienable sacred value of maintaining the general public's social participation. To that end, the federal government must be able to personify true leadership by developing a social policy on leisure(s)/recreation in Canada through timely public statements that will lead to achieving the policy. It therefore has the moral obligation and political duty to reassess its role, its goals, orientations, regulations and discretionary power to grant, in a spirit of service, additional and occasional financial resources. It is important to provide more appropriate subsidies in order to support, improve and strengthen the quality of life of citizens in Canada.

\subsubsection{A Framework for Recreation in Canada: Pathways to Wellbeing}

In terms of developing a common vision of leisure(s)/recreation through social policy, it is interesting to go back to the political thought of Ryan (2003), a master thinker on leisure(s)/[recreation] and a leading politician in the province of Quebec, who set out the first benchmarks of a true understanding of leisure(s)/[recreation] in terms of education and training, cultural and social, economic and the prospect of more promising jobs. For him, this human practice falls under the first categories of the following definition:

[Leisure(s)/[recreation] are] increasingly seen as a right for everyone. In order to ensure that attractive activities are available to all, it has rightly been concluded that the public sector should be involved in providing services. It is also generally accepted that the main stakeholder, as far as the public sector is concerned, should be the municipal level. The municipality is expected to make available to everyone services that are considered necessary today but which individuals cannot generally afford, such as parks, swimming pools, arenas, libraries, meeting places, sports facilities, etc. (trans. Ryan 2003, p. 11).

In an effort to describe a laudable effort in developing a social policy on leisure(s)/ recreation in Canada, it should be noted, however, that recently the Ministers of Leisure(s)/Recreation and Sport from all Canadian provinces and territories, with the exception of Quebec, jointly approved the document A framework for recreation in Canada: Pathways to wellbeing. This policy document sets the foundations and guidelines for a renewed social policy on leisure(s)/recreation in Canada from coast to coast. It delineates in a way some of the policies, guidance documents and action plans among Canadian provinces and territories in keeping with their specific social realities. It also suggests the following vision: "We envision a Canada in which everyone is engaged in meaningful, accessible recreation experiences that foster:

\footnotetext{
${ }^{7}$ Dumazedier (trans. 1988, p. 13) also ask this critical question: Why should we give more credence to the opinion of specialists who interpret in their own way, according to a priori systems, what persons do or declare? We have learned to be wary of those who claim to think for 'the population' or for 'humanity'.
} 
individual wellbeing, community wellbeing, the wellbeing of our natural and built environments" (Edwards 2014, p. 17). Five priorities for action are addressed in this seminal text for a national legislative agreement on leisure(s)/recreation in Canada:

1. Foster active living through physical fitness lifestyle by leisure(s)/[recreation];

2. Increase inclusion and access to leisure(s)/[recreation] for populations that face constraints to participation;

3. Help people connect to nature through leisure(s)/[recreation];

4. Ensure environments that are conducive to practice; and

5. Ensure the continued growth and sustainability of the leisure/[recreation] field (trans. Lavigne 2015, p. 1-4).

In any case, there is a flaw in the overall picture, because this policy document was weakened by the absence of Quebec's Minister of Education, Leisure(s) and Sport who, as mentioned earlier, did not attend this historic February 2015 meeting that was decisive for the future of social peace and a consolidated sense of living together. The result has been endless debates over the overlapping areas of powers and jurisdictions that Quebec is demanding. The question that arises above all else is how to complete this leitmotif in all humility, i.e.: 'a strong Quebec in a united Canada,' thus respecting 'Unity in diversity?' The renewal of national unity through a more inclusive multiculturalism fighting firmly against hatred and religious persecution can only be actualized in a hexis promoting cultural capital ${ }^{8}$ in the sustainability of social peace and a consolidated sense of living together.

The consequences of Quebec's absence from these leisure(s)/recreation social discussions are dramatic, since problems can suddenly arise in everyday life that has not been dealt with in a timely manner-nor indeed, in any manner whatsoever. In addition, faced with the present sanitary crisis cause by the Covid-19 pandemic context affecting Canada and other contemporary societies on Earth, the reduction of travelling around the world, job insecurity, early retirement and a desire to reintegrate seniors to the workforce, the increase of the cost of life (i.e., shelter, food, clothes, etc.), it is a worthwhile idea to take inspiration from reflection of Lavigne and Thibault (2016) who state that in the context of a society undergoing change, it appears this ability to think differently, to do better with less socially and administratively leads the population and decision makers to recognize professional expertise in leisure(s)/recreation. Nevertheless, the unease with leisure(s)/recreation is palpable. Although we live in a social reality in which the need to accomplish more with fewer and fewer resources are advocated, we are quickly realizing that we are destined to accomplish less with fewer resources and that the sharing of wealth and the rewarding of goods and services deliveries has become unequal among the Canadian population. Moreover, we are

\footnotetext{
${ }^{8}$ Cultural capital is a sociological concept developed by Bourdieu $(1979,1980,2001)$ in his theory of social reproduction. It describes the set of cultural resources available to individuals in their immediate family environment and in the school system. Based on a habitus being the intermediate reflection of a social world and its representations, it is a socio-economic asset that accumulates over time by being transmitted from generation to generation. It thus corresponds by extension to leisure objects such as books and dictionaries, monuments, CD-ROMs, videos, the press, radio and television, multimedia games, musics, works in museums, etc. These cultural goods are nowadays conveyed by mass entertainment through technological means such as the Internet and smart phones.
} 
reaching a point where Canadian society is relying on countless leaders of all stripes seeking political power at all costs while we are helplessly witnessing labour shortages that have become an inescapable problem.

\subsection{A Few Possible Solutions as a Prelude to Nationalwide Reflection}

For the purpose of better managing energy and resources in order to re-establish a viable balance that would correspond to a better management of time, one of the more feasible pragmatic solutions would be gradually moving towards the 4-day work week and the 3day leave (weekend) for all Canadian citizens (e.g., Dufour 1968). Reducing the work week in order to create more employment opportunities for as many people as possible is desirable (Turner \& Dumas 2016). In the face of social inequalities, many believe that one constraint is adequate management of pension funds. These authors advise delaying the onset of active participation in the labour force by supporting universal access to higher education and abolition of the retirement age. Doing that, however, pushes to the forefront the problem of the equitable distribution and sharing of wealth among Canadians. Furthermore, outrageous corporatism is becoming so unfair and deadly for the rising generations. Within the post-secularity era and the sanitary crisis cause by the Covid-19 pandemic context affecting Canada and other contemporary societies on Earth, it is crucial to identify support measures for work in order to increase free time and the activities of leisure(s)/recreation, including sporting practices. Here are a few of them:

[...] Flexible working hours, reduced working hours, equivalent working conditions for workers of all ages, possibility of sharing work with another employee, less demanding responsibilities, leave for personal reasons, part-time work, work schedule compressed into four days, possibility of doing part of the work at home, possibility of benefiting from training adapted to my personal needs, possibility of assignment to special projects, special salary bonuses, access to computer training programs, indexing of retirement pensions, access to certain social benefits, opportunities for career development, opportunities to develop one's employability, opportunities to take on new roles (Tremblay 2018, p. 11).

Tremblay (2018) had already emphasized that telecommuting and the mentorship inside the working force environment are relevant priorities to consider. In fact, they are now a reality in the communities of the social world. The capital insertion in the sanitary crisis cause by the Covid-19 pandemic context affecting Canada and other contemporary societies on Earth will also stimulate a renewed economy. Therefore, this situation created an inevitable increase in free time inciting new ways to manage leisure(s)/recreation, including sporting practices within complex matters of an ageing population and tight intergenerational connections. The post-secularity era in particular defined inevitably a new form of Christian faith and allows various policy-makers, who believe, according to the divine inspiration of the Wisdom of God to discover with empathy and flexible solutions at time and counter-time to face challenges that Canadians have to deal in everyday life. More precisely, this supposed adapted gestures which mean to suit the action to the word.

It is also important to strike the right balance - and it has to be done on a everyday basis - between the three major leisure(s)/recreation sectors, i.e., public leisure(s)/recreation, commercial leisure(s)/recreation and volunteerism (Karlis, 2016). For Thibault (2008), there 
is a remarkable trend in private leisure(s)/[recreation] that defines it as part of the habitus of cocooning or nesting. Subsequently, for this author, the person perceives leisure(s)/[recreation] as a moment of freedom and an opportunity to take care of oneself and those who make up his intimacy. For most Canadian citizens, these typologies of leisure(s)/recreation prioritize more or less lengthy periods of spiritual well-being. In that sense, Dumazedier (1962) testifies that leisure(s)/[recreation] is firstly the result of the increase of free time and any activity engaged freely by choice with the point of view of relaxation, entertainment and development functions. He also put forward this topical hypothesis:

$[\ldots]$ this leisure $[\mathrm{s}] /[$ recreation] is a time of social expression of oneself, individually or in a group. It is the place of emergence of a host of increasingly standard and varied social practices, more and more attractive and ambiguous which, while being limited and determined, exert an increasing influence on the whole of everyday life. [This time] can also be convivial, open to the world of things and beings, but above all centred on the individual or social requirement of personality. It can be devoted only to the passions of sport, crafts, televised entertainment, free friendly or romantic exchanges, but also to the practices of voluntary social commitments of all kinds (trans. Dumazedier 1988, p. 23, 205).

Also, the Covid-19 pandemic context caused an increase in leisure(s)/recreation time and more specifically a resurgence of spontaneous and informal leisure(s)/recreation including sports practices. Persons need guidance to manage this new reality in order to recover from mental health problems (Deschênes et al., 2015). From this point of view, there is an unavoidable need to innovate the university curriculum about courses in counselling on leisure(s)/recreation and sporting practices.

For the purpose of greater equity among the generations, a social policy on leisure(s)/ recreation in Canada cannot be achieved without a new consideration of sporting practices. Indeed, among the symptomatic effects that one can note are the distressing problems of obesity, physical inactivity [sedentarism] and stress in a society promoting a high-tech cybernetic model. Increasing attention is being paid to the importance of leisure(s)/recreation, including sporting practices, as a mobilizing and supportive agent for healthy lifestyle habits (such as controlling one's diet, limiting consumption of alcohol and/or soft drugs, taking medications, keeping stable work/play times, regular sleep hours, etc.). With that in mind, there is a pressing need to encourage and support mass sports participation by helping to include the vulnerable persons in society, such as women, First Nations, persons with a disability or disabilities, linguistic minorities and low-income families (Thibault \& Harvey 2013). For example, intramural sports participation has a prominent place in schools (Baldauf et al., 2011), accompanied by the allocation of funding that is both equitable and timely. There is reason to believe that a social policy on leisure(s)/recreation in Canada will promote intramural sports participation by creating strong links in the communities of the social world.

\section{Conclusion}

The objective of this conceptual article is to begin a reflection through dialogue to 'explain more' in order to 'better understand' the benchmarks of the pivotal need to 
develop a social policy on leisure(s)/recreation from a personalist point of view by studying the case of Canada. Existential questions are proposed, such as How to live? How to develop an innovative modus vivendi? and How to experience an art of living?, and this, between generations based on the spiritual model of leisure(s) that is the homo faber-religious-ludens within the post-secular era, knowing that persons can not always behave as if God does not exist in the communities of the social world. They are shedding further light on the realization that the goals of leisure(s)/recreation are a global earthly reality which is to enhance personal fulfilment, improve quality of life and regenerate the social fabric, because ultimately Canadian citizens co-exist in a single social world among the communities.

From a perspective in which monochronic and polychronic times are problematic and need to be clarified more fully as the time goes by, the urgency of the situation calls for a unifying definition of leisure(s)/recreation and sporting practices. Achieving such a definition is a major challenge to overcome in the face of power conflicts that prevent leisure(s)/recreation stakeholders from interacting with one another more effectively. Leisure/recreation and sporting practices are one of the preferred means of reducing unnecessary suffering and deserve careful consideration for the spiritual well-being of persons as they discover their own realm. Leisure(s)/recreation time becomes a vector of fundamental humanization that carries meaning and makes it possible to actualize the state of becoming based on ethical-spiritual moments. In the whole fundamental shift of a social policy on leisure(s)/recreation in Canada, it is important to remember that leisure(s)/recreation and sporting practices are vital places of culture through the manifestation of spiritualities that develop, one day at a time. A unified leisure(s)/ recreation definition in Canada will inspire other contemporary societies on Earth about social policies matters in this specific field of science and/or studies.

Most recently, A framework for recreation in Canada: Pathways to wellbeing was developed as a policy document, which was accepted by all the provinces and territories except for Quebec. It identifies five priorities for action that reflect Canada's national identity. Its purpose is to establish a common thread for a renewed synergy in the development of a social policy on leisure(s)/recreation from coast to coast in Canada by being an innovative reflection in the communities of the social world, in a renewed effort to ensure the sustainability of social peace and a consolidated sense of living together for each and every person. A few pragmatic recommendations are suggested as a first step in developing such a social policy for leisure(s)/recreation and sporting practices. It will in that way create more authentic cooperative links in order to promote harmony among persons by aiming for greater social solidarity in spite the sanitary crisis cause by the Covid-19 pandemic context affecting Canada and other contemporary societies on Earth.

\section{Recommendations}

As a follow-up to the reflections shared in this conceptual article, we propose the following:

- Develop a process of reflection aimed at establishing common ground between the different levels of government on the relevance of a social policy on leisure(s)/ recreation in Canada, a process that also involves leisure(s)/recreation professionals and consumers. 
- Organize a nationwide consultation that includes not just Canadian specialist thinkers and practitioners/stakeholders in leisure(s)/recreation, but one that also includes consumers of these goods and services deliveries. The purpose of this constraint negotiation strategy would be to better understand the missions of these three population groups in terms of leisure(s)/recreation, including sporting practices.

- Coordinate a Delphi survey for the co-development of meaning and knowledge of a unifying definition of the human leisure praxis with the help of Canadian specialist thinkers who are in tune with the particularities that define the Canadian mosaic.

- Organize the holding of discussion and/or debate groups to cultivate dialogue between the communities and socio-educational settings.

- Ensure that consultations include participants from various minority groups in society, including First Nations people, members of a variety of cultural groups and vulnerable persons to better understand their visions and perceptions of leisure(s)/recreation and sporting practices.

- National policies should take into consideration the new reality of informal and spontaneous leisure(s)/recreation and sports practices through the development of a social policy in that matter in which will be addressed not only to institutions but also the practitioners themselves.

"In the field of leisure the one policy will be to provide leisure facilities for the 'type of people' who need them; the other policy to stimulate an awareness of the possibilities of leisure-like behaviour in a variety of situations - including work". — Stanley Parker (1929-2012)

"Leisure is, [...] not just time and toys to be purchased by the real value of work. It is also a part of the wholness of life, of its balance and rhythms. If so, then the politics and policies of leisure are a matter worthy in a of public debate, dialogue, and decision".

— John 'Jack' Kelly

Acknowledgments The authors would like to express their thankfulness to Dre Julie Fortier who looked at the first version in French and gave some commentaries in order to improve the contents of this conceptual article. Also, a special thanks to Mr. Paul Johnston who translated the reading material from French to English.

\section{References}

Arendt, H. (1972). La crise de la culture. Paris: Gallimard. 
Baldauf, H., Byl, J., Raithby, A., Schwass, K., \& Wilson, C. (2011). Follow the leader. Ontario: Canadian Intramural Recreation Association.

Bellefleur, M. (1975-1976). Une certaine approche de l'idée de loisir. Loisir plus, 4(5-6), 16-17.

Bellehumeur, C. R., Deschênes, G., \& Malette, J. (2012). L'imaginaire au cœur du développement psychospirituel des jeunes: Une réflexion interdisciplinaire Sur la spiritualité de l'enfance et de la pré-adolescence. Studies in Religion/Sciences Religieuses, 41(1), 68-92.

Berger, P. L. (1970). Rumors of angels: Modern society and the rediscovery of the supernatural, Garden city, NY: Double \& Company, Inc.

Berger, P. (2001). La désécularisation du monde: Un point de vue global. In P. Berger (Ed.), Le réenchantement du monde (pp. 13-36). Paris: Bayard.

Berger, P. L., \& Luckmann, T. (1966). The social construction of reality: A treatise in the sociology of knowledge. Garden City, NY: Anchord Books.

Boeve, L. (2012). Religious education in post-secular and post-Christian context. Journal of Beliefs and Values: Studies in Religion and Education, 33(2), 143-156.

Bourdieu, P. (1979). Les trois états du capital culturel. Actes de la recherche en sciences sociales, 30, 3-6. http://www.persee.fr/doc/arss_0335-5322_1979_num_30_1_2654.

Bourdieu, P. (1980). Le Sens pratique. Paris: Minuit.

Bourdieu, P. (2001). La sociologie est un sport de combat/Sociology in a martial art. Paris: C.-P. productions/ Pierre Carles (VHS).

Bouwer, J. (2013). Leisure as moderator for spiritual well-being? In S. Heine \& H. Westerink (Eds.), Constructs of meaning and religious transformation: Current issues in the psychology of religion (vol. 4), (pp. 275-295). Göttingen, D: Vandenhoeck \& Ruprecht Unipress.

Burton, T. L. (1977). L’idée et la réalité. In T. Goodale, \&, C. Westland (Eds.), Le développement du loisir au Canada, iii-xii.

Caillois, R. (1958/1967). Les jeux et les hommes. Paris: Gallimard.

Canadian Index of Wellbeing. (2016). How are Canadians really doing? The 2016 CIW National Report. Waterloo, ON: University of Waterloo, Faculty of Applied Health Sciences.

Chamberland, G., Lavoie, L., \& Marquis, D. (2011). 20 formules pédagogiques. Québec, QC: Presses de l'Université du Québec.

Cullis, T., \& Suzuki, D. (2010). La déclaration d'indépendance: Un engagement envers la planète Terre. Montréal, QC: Boréal.

D’Amours, M. (1987). Les sciences du loisir: En compagnie de Max D’Amours, rôle du récréologue dans la société québécoise. Trois-Rivières, QC: Collections Carrefour (DVD).

Davidovich, N. (2017). The Sabbath as the ideal manifestation of leisure in traditional Jewish thought. In K. Spracklen et al. (Eds.), The Palgrave handbook of leisure theory (pp. 87-106). Palgrave Macmillan: London.

Demers, P. (2008). Élever la conscience humaine par l'éducation. Québec, QC: Presses de l'Université du Québec.

Demers, P. (2016). Vers Une conscience nouvelle: Éduquer pour humaniser. Sainte-Adèle, QC: Textes et Contextes.

Deschênes, G. (2007). Le loisir, une quête de sens: Essai de théologie pratique. Sainte-Foy, QC: Presses de l'Université Laval.

Deschênes, G. (2011). L'anthropologie spirituelle du loisir: L'homo faber-religiosus-ludens. Counseling \& Spiritualité/Counselling \& Spirituality, 30(2), 57-85.

Deschênes, G. (2015). Allégories appliquées à l'humain producteur-religieux-joueur: Le loisir comme outils thérapeutique. Counseling \& Spiritualité/Counselling \& Spirituality, 34(1), 59-89.

Deschênes, G. (2016). The homo faber-religiosus-ludens as a spiritual model of leisure through the aging process: A post-secular illustration of three Beatles songs. Counselling \& Spirituality/Counseling \& Spiritualité, 35(1), 47-66.

Deschênes, G. (2018). Scriptural illustration applied in the homo faber-religious-ludens spiritual model of leisure. Leisure/Loisir, 42(3), 259-279.

Deschênes, G., Heintzman, P., \& Reimer, J. (2015). Integrating religious and spiritual practices with therapeutic leisure within the recovery process of persons with mental disorders. Counselling \& Spiritualité/Counselling \& Spirituality, 34(2), 29-60.

Dufour, R. (1968). La spiritualité du week-end. Paris: Mame.

Dufour, R. (1980). Mythologie du week-end. Paris: Cerf.

Dumazedier, J. (1962). Vers une civilisation du loisir? Paris: Seuil.

Dumazedier, J. (1988). Révolution culturelle du temps libre 1968-1988. Paris: Méridiens/Klincksieck. 
Dumont, F. (1981). Une révolution culturelle? In F. Dumont, J. Hamelin, \& J.-P. Montminy (Eds.), Idéologies du Canada-François, 1940-1976, tome 1 (pp. 5-31). Québec, QC: Presses de l’Université Laval.

Durand, G. (1960/1992). Les structures anthropologiques de l'imaginaire: Introduction à l'archétypologie générale. Paris: Dunod.

Durand, G. (1964). L'imagination symbolique. Paris: Presses Universitaires de France.

Edwards, P. E. (2014). A framework for recreation in Canada: Pathways to wellbeing. Ottawa: Interprovincial Sport and Recreation Counsil/Canadian Parks and Recreation Association.

Gallant, K., Arai, S., \& Smale, B. (2013). Celebrating, challenging and re-envisioning serious leisure. Leisure/ Loisir, 37(2), 91-109.

Habermas, J. (2019). Wikipedia. Retrieved from <https://en.wikipedia.org/wiki/J\%C3\%BCrgen_Habermas>.

Hall, E. T. (1983). The dance of life: The other dimension of time. Garden City/Doubleday, NY: Anchor Press/ Doubleday.

Heintzman, P. (2000). Leisure and spiritual well-being relationships: A qualitative study. Loisir et Sociétél Leisure and Leisure, 23(1), 41-69.

Heintzman, P. (2008). Leisure-spiritual coping: A model for therapeutic recreation and leisure services. Therapeutic Recreation Journal Special Issue, 42(1), 56-73.

Heintzman, P. (2009). The spiritual benefit of leisure. Leisure/Loisir, 33(1), 419-445.

Huizinga, J. (1955). Homo ludens: A study of the play-element in culture. Boston, MA: Beacon Press.

Iwasaki, Y. (2018). Leisure and meaning-making: The pursuit of a meaningful life through leisure. In B. Beniwal, R. Jain, \& K. Spracklen (Eds.), Global leisure and the struggle for a better world (pp. 287-302). Cham, CH: Palgrave Macmillan.

Joblin, D. (2009). Leisure and sprituality: An engaged and responsible pursuit of freedom in work, play and worship. Leisure/Loisir, 33(1), 95-120.

Kant, E. (1781/1987). Critique de la raison pure. Paris: Flammarion.

Karlis, G., Grafanaki, S., \& Abbas, J. (2002). Leisure and spirituality: A theoretical model. Loisir et Sociétél Leisure and Leisure, 25(1), 205-214.

Karlis, G. (2016). Leisure and recreation in Canadian society: An introduction (3th ed.). Toronto, ON: Thompson Educational Publishing.

Kelly, J. (1987). Freedom to be: A new sociology of leisure. New York, NY: McMillan.

Kelly, J. R. (2012). Leisure. Urbana, IL: Sagamore Publishing LLC.

Kelly, J. R., \& Freysinger, V. J. (1999). $21^{\text {st }}$ century leisure: Current issues. Needham Heights, MA: Allyn \& Bacon.

Kraus, R. (2000). Leisure in a changing America: Trends and issues for the 21st century. Needham Heights, MA: Allyn \& Bacon.

Lavigne, M.-A. (2015). Une nouvelle politique canadienne du loisir: Analyse du cadre stratégique pour le loisir au Canada. Observatoire québécois du loisir, 12(13), 1-5.

Lavigne, M.-A., \& Thibault, A. (2016). Enjeux du loisir public québécois: Les dimensions administrative et professionnelle. Observatoire québécois du loisir, 13(16), 1-6.

Lefebvre, S. (2008). Cultures et spiritualités des jeunes. Montréal, QC: Bellarmin.

Lemieux, V. (2009). L'étude des politiques publiques: Les acteurs et leur pouvoir. Sainte-Foy, QC: Presses de l'Université Laval.

Lipovetski, G. (1983). L'ère du vide: Essai Sur l'individualisme contemporain. Paris: Gallimard.

Lipovetski, G. (1987). L'empire de l'éphémère. Paris: Gallimard.

Martin, A. R. (1975). Leisure and our inner ressources. Park and Recreation, 10, 1a-16a.

Moulaert, T., Biggs, S., \& Caradec, V. (2015). Repenser l'avancée en âge au temps du vieillissement actif. In J. P. Viriot Durandal, É. Raymond, T. Moulaert, \& M. Charpentier (Eds.), Droits de vieillir et citoyenneté des aînées: Pour Une perspective internationale (pp. 269-296). Sainte-Foy, QC: Presses de l'Université du Québec.

Mounier, E. (1952). Personnalism. London: Routledge \& Kegan Paul Ltd..

Nash, J. B. (1953). Philosophy of recreation and leisure. St Louis, MO: C.V. Mosby.

Neulinger, J. (1974/1981). The psychology of leisure. Springfield, IL: Charles C. Thomas Publisher.

Ouellette, P., Snyder, P., \& Carette, R. (2011). L'application de la spiritualité bénédictine au loisir des personnes âgées: Un modèle théorique du bonheur spirituel. Studies in Religion/Sciences Religieuses, $40(1), 21-44$.

Pageot J.-C., (1977). Réaction à la communication de F. Brégha: Les aspects sociaux de l'organisation des loisirs au Canada. In T. Goodale, \& C. Westland, (Eds.), Le développement du loisir au Canada, 28-33.

Paplauskas-Ramunas, A. (1960). L'éducation physique dans l'Humanisme intégral, $2^{e ̀ m e ~ e ́ d i t i o n . ~ O t t a w a, ~ O N: ~}$ Presses de l'Université d'Ottawa. 
Paré, J.-L. (1985). Loisir et style de vie: Pour des approches diversifiées et explicites en recherche. Loisir et Société, 8(2), 405-424.

Paré, J.-L. (1997). L'intégration du migrant par les loisirs. In M. Gauthier (Ed.), Pourquoi partir? La migration des jeunes d'hier et d'aujourd'hui (pp. 189-212). Québec, QC: Presses de l'Université Laval.

Parker, S. (1975). The sociology of leisure: Progress and problems. The British Journal of Sociology, 26(1), 99-101.

Parker, S. (1983). Leisure and work. London: George Allen \& Unwin Publishers.

Pieper, J. (1952). Leisure: The basis of culture. New York, NY: Pantheon Books.

Pronovost, G., Attias-Donfut, C., \& Samuel, N. (Eds.). (1993). Temps libre et modernité: Mélanges en l'honneur de Joffre Dumazedier. Sainte-Foy, QC/Paris: Presses de l'Université du Québec/L'Harmattan.

Ricœur, P. (1992). Oneself as another. Chigago, IL: The University of Chicago Press.

Robinson, J. P., \& Godbey, G. (1997). Time for life : The surprising ways Americans use their time. University Park, PA: The Pennsylvania State University Press.

Robinson, P. (2019). Rules, rights, and values: Contradictions in the post-secular Liberal international order. Paper presented at a conference at the Moscow state Institute of International Relations (MGIMO). This has now been published, in russian, in the latest edition (2019, no. 3) of 'Tetradi po konservatizmu' ('notebooks on conservatism'). Abstract retrieved from <https://irrussianality.wordpress.com/2020/03/04 /post-secularism-and-the-liberal-international-order/>, 1-6.

Ryan, C. (2003). Allocution d'ouverture de monsieur Claude Ryan, président d'honneur du forum québécois du loisir 2003. Montréal, QC: Conseil québécois du loisir, 1-15.

Sénèque (49-55 a.p. J.-C./1994). Sur la brièveté de la vie. Paris: Mille et une nuits.

Schor, J. B. (1992). The overworked American: The unexpected decline of leisure. Grand Rapids, MI: Baker Books.

Spohn, W. C. (2007). Jesus and ethic: Go and do likewise. New-York, NY: The Continum International Publishing Group Inc..

Statistique Canada (2018). Enquête sociale générale: Aperçu Sur l'emploi du temps des Canadiens. Fichier PDF.

Storey, T. E. (1990). The quest for a national policy on recreation: A brief history. Recreation Canada, 48(2), $7-10$.

Sue, R. (1994). Temps et ordre social. Paris: Presses de l'Université de France.

Suzuki, D. with McConnell, A. \& Mason, A. (2007). The sacred balance: Rediscovering our place in nature. Vancouver: Greystone Books.

Taylor, C. (1992). Grandeur et misère de la modernité. Montréal, QC: Bellarmin.

Thibault, A. (2008). Le loisir public et civil au Québec: Dynamique, démocratique, passionnelle et fragile. Québec, QC: Presses de 1’Université du Québec.

Thibault, L., \& Harvey, J. (2013). Sport policy in Canada. Ottawa, ON: University of Ottawa Press.

Torjman, S. (2005). What is policy? Ottawa, ON: Caledon Institute of Social Policy. 1-24.

Tremblay, D.-G. (2018). Quelles fins de carrière pour les travailleurs vieillissants? Réalités et préférences en matière de temps de travail. Vie et vieillissement, 15(4), 4-13.

Turner, B. S., \& Dumas, A. (2016). L'anti-vieillissement: Vieillir à l'ère des nouvelles biotechnologies. SainteFoy, QC: Presses de l'Université Laval.

Zauhar, J. (1985). Éducation/Counselling en loisir: Cours magistral à l'Université d'Ottawa.

Weber, M. (1904-1905/1964). L'éthique protestante et l'esprit du capitaliste. Paris: Plon.

Weber, M. (1919/1959). Le savant et le politique. Paris: Plon.

Publisher's Note Springer Nature remains neutral with regard to jurisdictional claims in published maps and institutional affiliations. 